\title{
Investigating the nutritional quality of the dietary provision for the under fives
}

\author{
J. Young, C. L. Marshall, H. J. Haywood, V. C. Moffet, C. Raper, H. Matthews, S. R. Wilson, \\ T. L. Kelly and T. W. George \\ Department of Applied Sciences, Faculty of Health and Life Sciences, Northumbria University, Newcastle upon Tyne, \\ NE1 8ST, UK
}

With an increase in adult disease relating to poor diet choices, the early years are a crucial time for intervention. Obesity in childhood is more likely to lead to obesity in adulthood and the associated risks of age-related diseases such as CVD and diabetes. These and other agerelated diseases including osteoporosis and bone fracture have been linked to specific nutrients such as particular fats, cholesterol, GI, fibre, fruits, vegetables, calcium and vitamin $\mathrm{D}^{(1)}$. The nursery setting offers an excellent opportunity to deliver food messages and practices that can either have a positive or a negative effect on the child's health ${ }^{(2)}$ with long-lasting consequences. The current project was a pilot study comprising 12 nurseries from the NE of England; food provision comparisons were made between nurseries who had received council-run nutrition training (group A) with those that had no training (group B) using ANOVA and T tests. Data was compared with the Caroline Walker Trust ${ }^{(3)}$ dietary requirement guidelines for children between the ages of 1-4.

Significant differences $(p=.000)$ were found between nursery group A and group B in fruit provision but not for vegetable provision and for the provision of sodium, group B having a significantly lower $(p=0.039)$ content of sodium provision (Fig. 1). No significant difference was reported for total energy provision or for fat, protein and carbohydrate as percentage of energy provision between groups A and B. No significant differences were noted between A and B with respect to the provision of carbohydrate, total fat, SFA, MUFA, PUFA, omegas 3 and 6, vitamin D, iron or zinc. However, both groups were deficient in iron and zinc provision and both groups failed to achieve half of the required daily RNI for vitamin D.

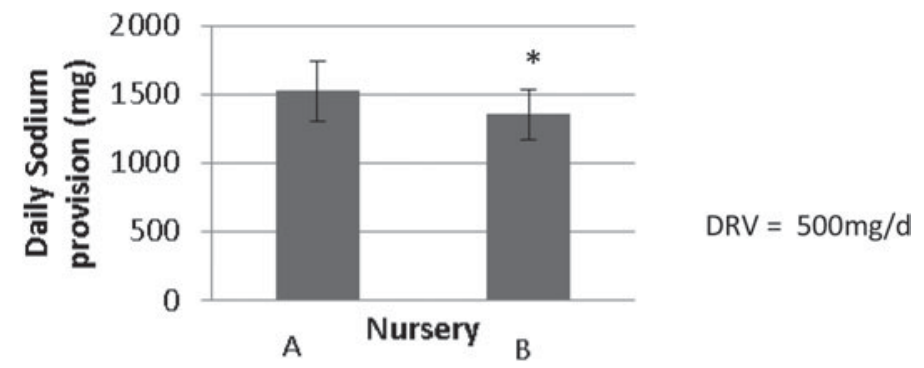

Fig. 1. Comparison of average sodium provision for nurseries in group A $(n=6)$ and group $\mathrm{B}(n=6) \pm$ stdev where significance is denoted by $*(p<0.05)$. DRV for sodium for $1-3 \mathrm{yrs}=500 \mathrm{mg} / 4$.

Sodium provision for all nurseries was more than twice the DRV of $500 \mathrm{mg} / \mathrm{d}$ for a child aged 1-3 years, with some group A nurseries providing over $1500 \mathrm{mg} / \mathrm{d}$. Total fat and SFA were higher in group A than B and trans fat was significantly higher in group B than A $(p=0.010)$. The daily mean values for both groups A and B were higher than the recommended $\%$ of total energy intake and both groups were below the recommended level for omega 3. The study will be extended to incorporate a larger number of nurseries within other areas of NE of England.

1. Everitt AV, Hilmer SN, Brand-Miller JC, Jamieson HA, Truswell AS, Sharma AP, Mason RS, Morris BJ, Le Couteur DG (2006) Dietary Approaches that Delay Age-Related Diseases. Clin Interv Aging 1(1), 11-31.

2. Jacobi C, Agras WS, Bryson S, Hammer LD. 2003. Behavioral validation, precursors, and concomitants of picky eating in childhood. $J$ Am Acad Child Adolesc Psychiatry 42, 76-84.

3. Caroline Walker Trust 2006. Eating Well for Under-Fives in Child Care report ( $2^{\text {nd }}$ Edition) Wordworks, London 